\title{
Simultaneous representations of explanatory characteristics of mergers
}

\author{
R.C. van den Honert and G.D.I. Barr \\ Department of Mathematical Statistics, University of Cape Town, Private Bag, Rondebosch, 7700 Republic of South Africa
}

Accepted 18 April 1988

\begin{abstract}
In this paper we consider the effect of various explanatory characteristics on target and acquiring firm shareholder's wealth using a specialized graphical technique. Whereas previous analyses have considered each of the characteristics in isolation we analyse all the characteristics simultaneously by using the covariance biplot. By analysing the resulting single diagram for acquiring firms and target firms we are able to present information about the relative variability or riskiness of each level of the five characteristics, as well as about their comovement.
\end{abstract}

\begin{abstract}
Ons ondersoek die effek op die kumulatiewe gemiddelde abnormale opbrengs van oornemende en oorgenome maatskappye wat in samesmeltings betrokke is op twee vlakke van vyf eienskappe elk wat samesmeltingsaktiwiteit beskryf op aandeclhouersrykdom. Waar vorige analise clk van die cienskappe in isolasie ontleed het, ondersock ons al die eienskappe tegelyk deur middel van die kovariansie-tweepuntgrafiek. Deur die kovariansie-tweepuntgrafiek vir oornemende en oorgenome maatskappye te ontleed kan ons informasie kry omtrent die relatiewe veranderlikheid of risiko van beide vlakke van dic vyf eienskappe, sowel as omtrent hulle samebeweging.
\end{abstract}

\section{Introduction}

Much recent work in the financial literature has covered the field of mergers and acquisitions, and specifically the distribution of any wealth changes between the parties participating in the merger. Affleck-Graves, Flach \& Jacobson (1988) have considered the returns accruing to shareholders of acquiring and target firms on the Johannesburg Stock Exchange (JSE), and established that shareholders of the acquired firms experience abnormal positive returns immediately prior to the announcement date, but found no evidence of gains to the shareholders of the acquiring firms. Bhana (1987) also found evidence that shareholders of acquired companies earned substantial abnormal returns around the time of the take-over announcement. These results are consistent with recent work done on the New York Stock Exchange (see, for example, Halpern (1973), Mandelker (1974), Langetieg (1978), and Dodd (1980)). This work was extended by van den Honert, Barr, Affleck-Graves \& Smale (1988) who examined how the level of abnormal returns experienced by shareholders was related to four different characteristics of merger, namely the relationship between acquiring and target firms, their relative sizes, the amount of prior control of the acquirer in the target and the medium of exchange. In this work, however, each of the four characteristics were considered in isolation for acquiring firms and target firms. No attempt was made to analyse the characteristics simultaneously so as to supply information as to the relative strengths and weaknesses of these characteristics with respect to one another through time.

The covariance biplot, a multivariate statistical graphical tool devised by Gabriel $(1971,1972,1981)$, is a particularly useful means of demonstrating the relationships in the type of multivariate time series data described above. Indeed, Barr \& Affleck-Graves (1987) showed that the method can be used to track the relative strength of several share portfolios (consisting of sector indices) on the JSE. Furthermore the riskiness of each of the sector indices can be inferred from the covariance biplot and the correlations between the various sector indices.

In this paper we demonstrate how the relative influence of five explanatory characteristics of merger activity (around the merger announcement) can be determined by the analysis of a single covariance biplot diagram. This method of analysing the effect of these characteristics has the distinct advantage over the cumulative average abnormal return methodology usually employed since several characteristics can be considered simultaneously and with relation to one another, and not merely in isolation. Furthermore, specific information regarding the risk and co-movement of each characteristic is obtained.

\section{The covariance biplot interpretation}

The covariance biplot is a specialized graphical technique for the display of an $n \times m$ data matrix of points. In this application the $n$ rows represent successive time points and the in columns represent the distinguishing characteristics of merger activity to be discussed below. In the biplot each of the $n$ rows and $m$ columns are represented as a single point in a low (usually two) dimensional subspace, creating two overlapping clouds of points in such a way that the maximum amount of the variability in the data matrix is captured. The mathematical procedure involved has been extensively reviewed by Gabriel $(1971,1981)$, Greenacre \& Underhill (1982). Greenacre (1984) and Barr \& Affleck-Graves (1987) and we therefore concentrate on the geometrical interpretation of the features of the biplot relevant to this study.

It should be noted that for practical applications the $n$ $\times m$ matrix will be mapped onto only two dimensions and thus the biplot produced will only be an approximation of the perfect biplot. The quality of this approximation can be calculated in terms of the two 
largest eigenvalues of the data matrix (Greenacre, 1984). Thus, the properties described below are approximately true in two dimensions.

The geometrical interpretation is in terms of the distances of each point from the origin (centre) of the biplot and the cosines of the angles which pairs of points subtend at the origin:

1. The distance of each column point from the origin of the plot represents the standard deviation of the column. So if column 1 plots closer to the origin than does column 2 , it has a smaller standard deviation than does column 2 irrespective of the direction of each of the two points from the origin. Considering that in this application column points represent vectors of returns amongst firms quoted on the stockmarket, the standard deviation of each of the column points provides a measure of the risk of each of the column points (Markowitz, 1952).

2. The cosine of the angle two column points subtend at the origin represents the correlation between the two points. Thus, if the angle between two points is small the correlation between the two points will be very large (close to 1) since cosine $\left(0^{\circ}\right)=1$. Similarly, if the two points are diametrically opposed to one another their correlation will be close to -1 since cosine $\left(180^{\circ}\right)=-1$. Two points orthogonal to one another are uncorrelated, since cosine $\left(90^{\circ}\right)=0$.

3. The relationship between the rows and the columns of the matrix is related to the distance of the row point and column point from the origin and the angle between the points. Specifically, the element in the $i$ th row and the $j$ th column is represented by the product of the distances of both the $i$ th row point and $j$ th column point from the origin and the cosine of the angle subtended by the two points at the origin. So if a row point plots close to a column point the angle between them will be small and the row point will have a large value, one which is above the mean of

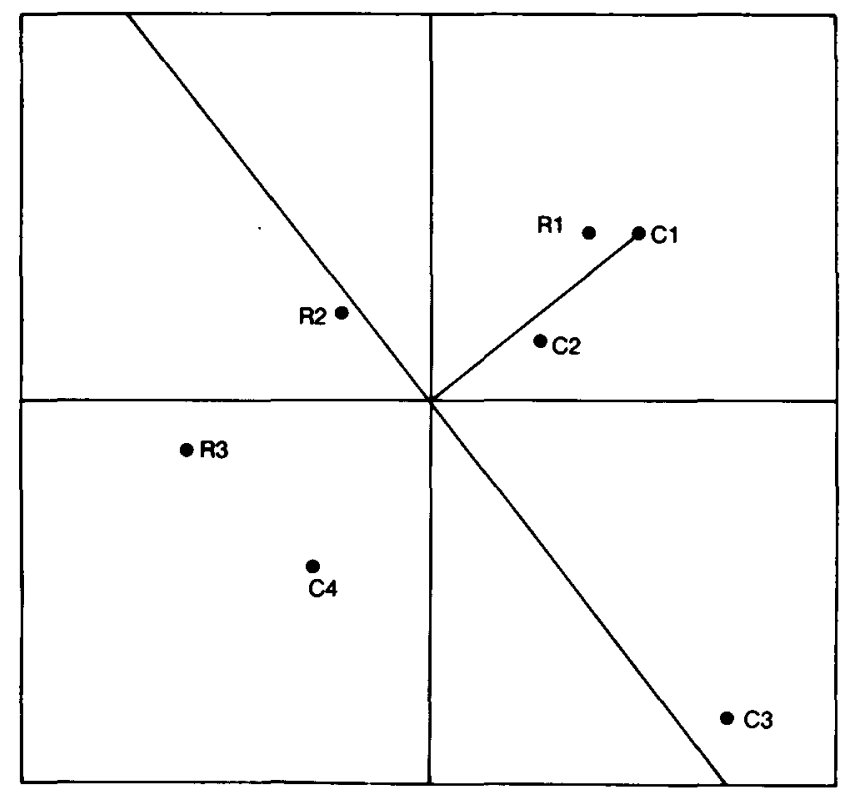

Figure 1 Covariance biplot for a matrix with three rows and four columns that column. Conversely, if a row point plots in the opposite half plane to a column point the angle between them will be large and the row point will have a value which is below the mean of that column. The above properties are shown in Figure 1, a (perfect) two-dimensional biplot of a hypothetical $3 \times 4$ matrix. It will be seen that column points $\mathrm{C} 1$ and $\mathrm{C} 2$ subtend a small angle at the origin, implying that columns 1 and 2 of the matrix are highly correlated. Similarly columns 1 and 4 are highly negatively correlated, since points $\mathrm{C} 1$ and $\mathrm{C} 4$ subtend a large angle at the origin. Points $\mathrm{C} 1$ and $\mathrm{C} 3$ are at right angles to one another, so columns 1 and 3 are uncorrelated. Furthermore, column 2 has the smallest standard deviation since $\mathrm{C} 2$ is closest to the origin, whilst column 3 has the largest standard deviations since $\mathrm{C} 3$ is furthest from the origin.

Furthermore, row point $\mathrm{Rl}$ is close to column point $\mathrm{Cl}$ subtending a small angle at the origin whilst row point R3 lies far away from $\mathrm{Cl}$ and they subtend a large angle at the origin. Thus row 1 of column vector 1 is large relative to the mean of column vector 1 and row 3 of column vector 1 is relatively small. Row 2 is approximately orthogonal to column point $\mathrm{C} 1$ and therefore row 2 is neither large nor small.

If the row points represent a time series then the relative strengths and weaknesses within a particular column vector can be tracked through time by joining the row points in time order and using the preceding interpretation. Therefore a movement of the row points away from a column point on the biplot implies a relative weakening of that column variable (relative to its mean) and a movement towards a column point implies a relative strengthening. A movement at right angles to a column point implies neither a strengthening nor a weakening.

\section{Methodology}

To illustrate how the covariance biplot is such an effective tool for analysing the relative movements of various characteristics involved in mergers and acquisitions, 33 acquiring firms and 40 target firms involved in mergers on the Johannesburg Stock Exchange over the period 1975 - 1985 were identified. Over this period many more mergers occurred on the JSE, but many potential acquiring and target firms failed these criteria:

1. The acquiring firm must not have engaged in two mergers less than one year apart.

2. The average annual trading volume of the acquiring firm's shares (calculated over the four years prior to the merger and the year subsequent to the merger) had to have been greater than 100000 . Many shares quoted on the JSE are thinly traded, thus reducing the efficiency of the market in those shares, a basic assumption of this research.

3. The announcement date had to be between March 1976 and March 1985 to ensure at least one year's weekly share price data on either side of the merger announcement date. 
A complete list of the selected firms can be found in Appendices 1 and 2.

Weekly closing prices for the chosen acquiring and target firms were collected starting from a period 60 weeks prior to the merger annnouncement and running through to 60 weeks after the announcement (12 weeks after the announcement in the case of the target firms, as this is the earliest date after the announcement that target firms begin to get delisted).

Throughout this study all computations were based on returns rather than the original price data. The weekly returns over this period were calculated as

$R_{i t}=\log _{e}\left(\left(P_{i t}+D_{i t}\right) / P_{i t-1}\right)$

where $R_{i t}=$ return on share $i$ in period $t ; P_{i t}=$ price of share $i$ in period $t ; P_{t t-1}=$ price of share $i$ in period $t-1$; and $D_{i t}=$ amount of dividends paid on share $i$ in period $t$.

The returns on the market (represented by the JSE Industrial Index) were computed using the same method.

The returns for each acquiring and target firm as well as the market were added for each successive four-week period to yield four weekly returns (from now on we will refer to these four-week returns as monthly returns). This was done merely to keep the number of plotted time points on the covariance biplot around the time of the merger announcement manageable to avoid confusion in the interpretation. To remove market-wide information from the security monthly returns in order to focus on merger-specific information, the market model as used by Fama, Fisher, Jensen \& Roll (1969) was fitted to the data. This model can be written in stochastic form as

$R_{i t}=\beta_{0}+\beta_{1} R_{m t}+\epsilon_{i t}$

where $R_{i t}=$ return on share $i$ in period $t ; R_{m t}=$ return on the market in period $t ; \epsilon_{i t}=$ stochastic error term; and $\beta_{0}$ and $\beta_{1}$ are the regression coefficients.

The parameters $\beta_{0}$ and $\beta_{1}$ of the model in equation (1) were estimated using ordinary least squares regression. An estimate of expected returns for each share for each month for the thirty-month period surrounding the merger announcement was then calculated by taking the expectation of model (1) above. This yields

$E\left(R_{i t}\right)=\hat{\beta}_{0}+\hat{\beta}_{1} R_{m t}$

where $\hat{\beta}_{0}$ and $\hat{\beta}_{1}$ are the ordinary least squares estimates of $\beta_{0}$ and $\beta_{1}$ respectively. The difference between the actual monthly return observed for any share $i$ in period $t$ and the expected value of this return as calculated in equation (2) is that part of the return unrelated to the market, and is known as the residual for share $i$ in period $t, \mathrm{Y}_{\mathrm{it}}$. Thus

$Y_{i t}=R_{i t}-E\left(R_{i t}\right)$
The residuals were calculated for each of the 33 acquiring firms for the 30 months around the merger announcement and for the 40 target firms for the 15 months before and the three months after the announcement.

Since the role of the covariance biplot analysis is to determine the relative effect of various characteristics which explain the merger activity with respect to one another and with respect to time, groupings were constructed for both acquiring and target firms according to two levels of each of five characteristics. The characteristics employed in this study were:

1. Relative size of the target firm to the acquiring firm as measured by the ratios of their market capitalizations at the time of the merger announcement. A firm had large relative size $(>60 \%)$ or small relative size $(<$ $30 \%$ )

2. Systematic risk prior to the merger announcement (the beta coefficient calculated in equation (1) above). This was classified as high $(\mathrm{B}>1,00)$ or low $(\mathrm{B}<0,80)$.

3. Prior holdings of the acquiring firm in the target firm at the time of the merger announcememnt. This was either large $(>60 \%)$ or small $(<40 \%)$.

4. The relationship between the acquirer and the target. A merger was classified as 'related' if the target firm was in a related industry to the acquiring firm and the acquiring firm was operating in a specific industry, i.e. was not of a conglomerate nature. All other mergers were classified as 'unrelated'.

5. The medium of exchange used in financing the merger. This was classified either as cash only or shares only.

It will be noted that the two levels of the first three characteristics above are not exhaustive. This is merely to ensure maximum discrimination between the two levels of the characteristics concerned.

Except for the first characteristic mentioned above (systematic risk) the characteristics considered were those which were analysed by van den Honert $e t$ al. (1988). This provides an interesting comparison and highlights the use of the covariance biplot.

The division of the acquiring and target firms into each of the two levels of the five characteristics can be found in Appendices 1 and 2. Average residuals for each period were calculated for the subset of shares in each level of the five characteristics. Thus the average residual for grouping $j(j=1,2, \ldots, 10)$ in time $t$ can be written as

$\bar{Y}_{j t}=\sum_{i=1}^{n_{j}} Y_{j t} / n_{j}$

where $\bar{Y}_{j t}=$ average residual for grouping $j$ in time $t ; Y_{j, t}$ $=$ residual for share $i$ in grouping $j$ in time $t$; and $n_{j}=$ number of shares in grouping $j$. 
The average residuals were cumulated from 15 months prior to the merger announcement through to 15 months after the announcement for acquiring firms ( 30 periods) and three months after the announcement (18 periods) in the case of target firms. The cumulated average residuals for grouping $j$ in month $p$ relative to the merger announcement ( $p$ th month in 'announcement time') may be calculated as

$$
C U M Y_{j p}=\sum_{t=-15}^{p}\left[\sum_{i=1}^{n_{j}} Y_{j, l} / n_{j}\right]
$$

The sequence of $30 C U M Y_{j p}$ values for acquiring firms and $18 C U M Y_{j p}$ values for target firms for each of the 10 groupings provided the input for the covariance biplot. The sequence of $C U M Y_{j p}$ values for each grouping plots as a single point in two-dimensional space. The biplot method interprets the value of the cumulative average residuals at each time point for each grouping in an absolute sense, as well as the movements of the cumulated average residuals at each time point for each grouping relative to each of the other groupings at the same point in time.

\section{Results}

The output of the covariance biplot in two dimensions for the acquiring firms for the 15 months before and 15 months after the merger announcement is shown in Figure 2. The numerals 1 to 10 represent each of the two levels of the five characteristics discussed above, in the following order:

1. small relative size

2. large relative size

3. small beta coefficient
4. large beta coefficient

5. small prior holdings

6. large prior holdings

7. related mergers

8. unrelated mergers

9. share exchange

10. cash exchange.

The time points are represented by the letters $A$ to $Z$ through a to $d$, where $A$ represents the monthly period 15 months prior to the merger annnouncement, B represents the monthly period 14 months prior to the announcement, etc. Thus $\mathrm{O}$ represents the period in which the merger announcement occurred.

The quality of the biplot in two dimensions is $88,50 \%$, indicating that the distortion in the two-dimensional display should be acceptably small.

The standard deviation of each of the groupings considered (columns in the original matrix) is a measure of the variability or total risk of that grouping and is indicated on the covariance biplot by the squared distance of the point from the origin as discussed above. With reference to Table 1 and Figure 2 it will be seen that the acquiring firms with small betas prior to the merger announcement (3) are the most risky when measured over the entire period under consideration, followed by the acquiring firms which are large relative to the target firms (2), and the acquiring firms which use shares as a means of exchange (9).

Related acquiring firms (7), those acquiring firms with small prior holdings (5) and with large prior holdings (6), have similar risk, amounting to approximately half of that of the acquiring firms with small systematic risk (beta), even though they lie in different directions from the origin. Cash exchange acquirers (10) and especially relatively small acquirers (1) have the smallest risk over

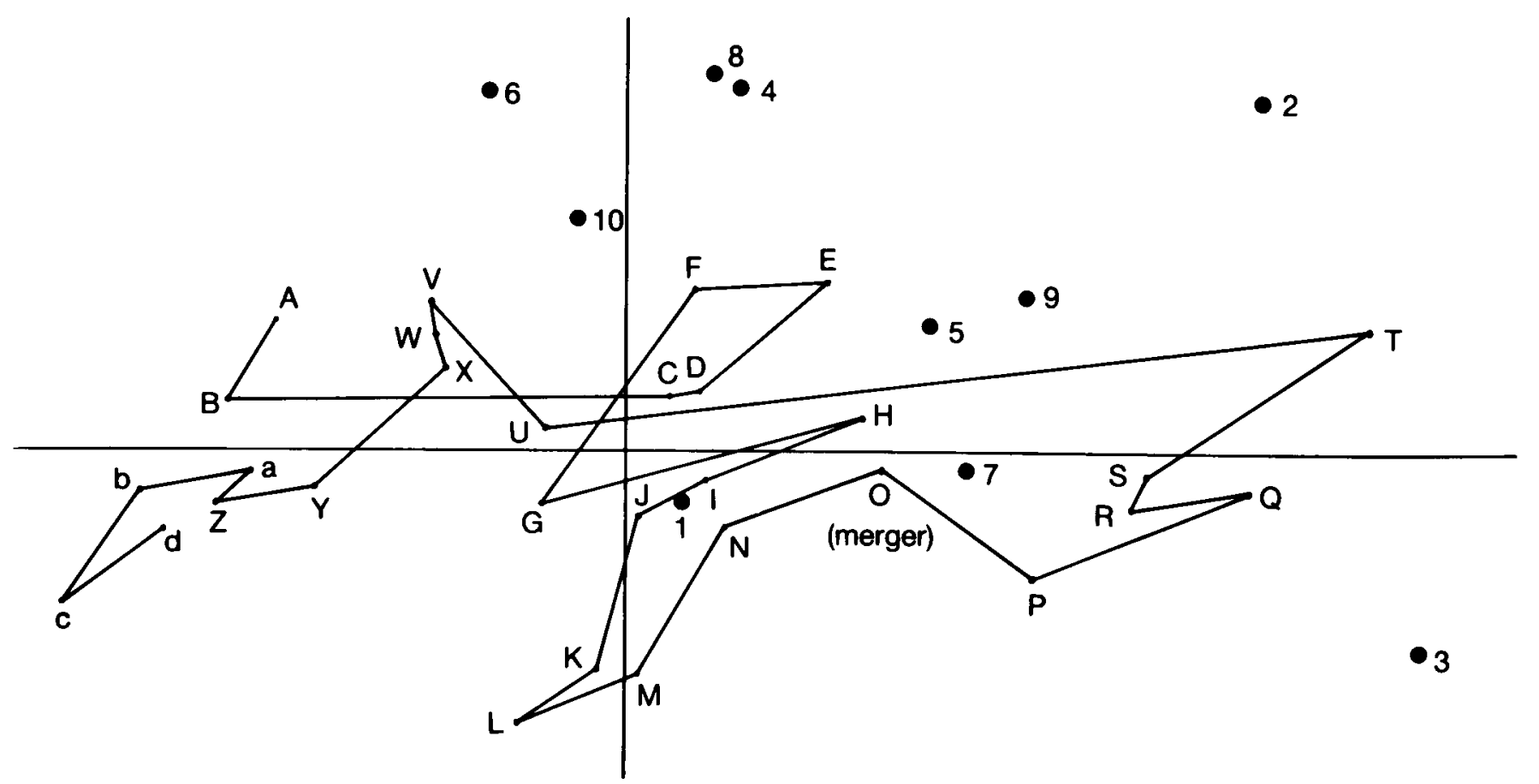

Figure 2 Covariance biplot for two levels of five characteristics of acquiring firms over the period 15 months prior to merger until 15 months after merger 
Table 1 Correlation matrix (standard deviations on diagonal) for acquiring firms

\begin{tabular}{lrrrrrrrrrrr}
\hline Small size & 0.016 & & & & & & & & \\
Large size & 0,064 & 0,064 & & & & & & & \\
Small beta & 0,397 & 0,775 & 0,092 & & & & & & \\
Large beta & 0,326 & 0,619 & 0,314 & 0,028 & & & & & \\
Small prior holdings & 0,572 & 0,737 & 0,808 & 0,578 & 0,042 & & & & \\
Large prior holdings & $-0,247$ & $-0,234$ & $-0,524$ & $-0,190$ & $-0,360$ & 0,038 & & & & \\
Related mergers & 0,293 & 0,861 & 0,946 & 0,329 & 0,819 & $-0,380$ & 0,042 & & & \\
Unrelated mergers & 0,482 & 0,537 & 0,329 & 0,828 & 0,645 & 0,174 & 0,361 & 0,023 & & \\
Share exchange & 0,410 & 0,897 & 0,903 & 0,628 & 0,908 & $-0,431$ & 0,925 & 0,596 & 0,050 & \\
Cash exchange & $-0,012$ & $-0,233$ & $-0,348$ & $-0,180$ & $-0,235$ & 0,826 & $-0,247$ & 0,260 & -0.351 & 0,020 \\
\hline
\end{tabular}

the period 15 months prior to the merger to 15 months after the merger. These results are consistent with those of van den Honert et al. (1988) after a visual comparison. In that paper it was shown that large acquiring firms had abnormal returns which were very much more variable than those of small acquiring firms, share exchange acquirers had residuals which were somewhat more variable than cash exchange acquirers, and related and unrelated mergers had residuals which were almost equal in terms of variability. The covariance biplot has the advantage of representing all the above results on a single plot.

The cosine of the angle between two grouping points is representative of the correlation between the two groupings as discussed above. From Figure 2 and the correlations given in Table 1 we see that several groupings are very highly correlated, notably cash exchange acquirers (10) and acquirers with large prior holdings (6) (correlation $=0,826$ ), unrelated acquirers (8) and those with large systematic risk prior to the announcement (4) (correlation $=0,828$ ), share exchange acquirers (9), acquirers with small prior holdings in the target firm (5) and acquirers which are large relative to the target firm size (2) (pairwise correlations between 0,737 and 0,908 ) and finally those acquirers with small systematic risk (3) and those which were related to the target firm (7) (correlation $=0,946$ ). These results are consistent with those of van den Honert et al. (1988) after a visual comparison. Furthermore it is seen that firms with small systematic risk (3), those with small size relative to the target firm (1) and the related acquiring firms (7) tended on average over the period to move in the opposite direction to the cash exchange acquirers (10) and those with large prior holdings (6) (negative correlations ranging between $-0,247$ and - 0,524). Since the firms with small relative size (1) are approximately orthogonal to those with large relative size (2) it can be inferred that they are uncorrelated (correlation = $0,064)$.

The letters representing the time points relative to the merger announcement have been joined in time sequence to facilitate easy interpretation as discussed above. It may be seen that for the first five-month period (time points $A$ to $E$ ) of the study the movement is towards the centre of the biplot and, more specifically, towards the acquirers with small prior holdings in the target firms (5) and those that employed shares as a medium of exchange (9). Thus firms represented in these two groupings were gaining in strength relative to firms that were not represented in these groupings. The movement is then reversed for two months (time points $F$ and $G$ ) indicating that the cumulative average residuals for all firms are decreasing, particularly the relatively large acquirers (2), the unrelated acquirers (8) and those with large systematic risk prior to the announcement (4). There follows a sharp reversal for one month (time point $\mathrm{H}$ ) in which the acquirers with small prior holdings (5), share exchange acquirers (9) and related acquirers (8) gain in strength relative to all other groupings while all firms not represented in these groupings neither gain nor lose. Then follows a fourmonth reversal (time points I to $\mathrm{L}$ ) where the cumulative average residuals of all firms decrease, followed by the three-month period immediately preceding the merger where the largest relative gains in cumulative average residuals are made by the relatively small acquirers (1) and, most of all, the related acquirers (7) (time points $M$ to $O)$. Immediately after the merger the movement is away from the aforementioned groupings until the end of the period under study (points $P$ to $d$ ), indicating a decrease in residuals for all the groupings under study. The use of the covariance biplot as a single diagram with

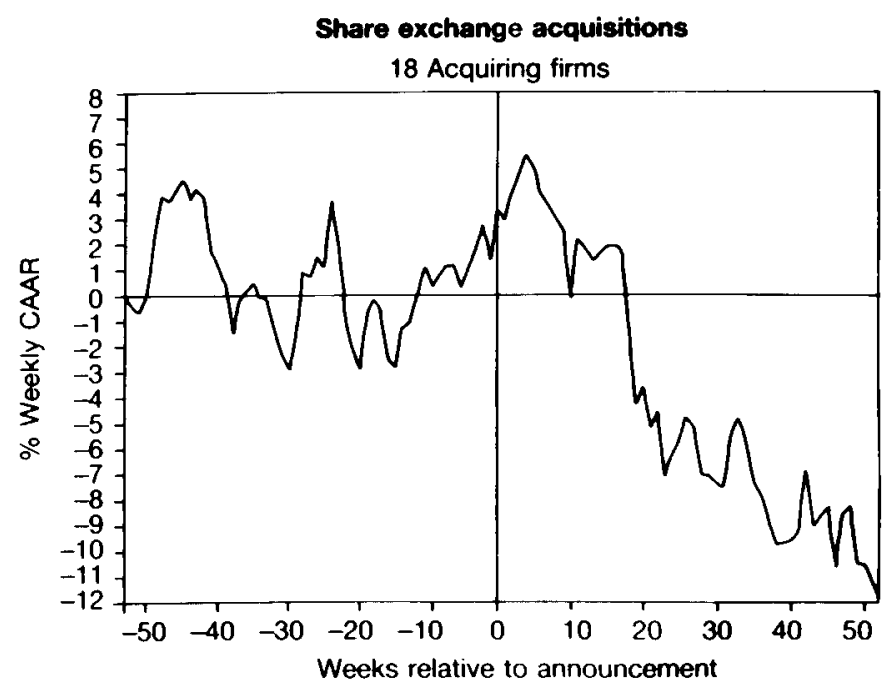

Figure 3 CAAR plot for acquiring firms in share exchange mergers (Source: Van den Honert et al., 1988) 
all the pertinent information contained in van den Honert et al. (1988) can be seen by studying Figure 2 in conjunction with the cumulative average abnormal residual (CAAR) plots for share exchange acquirers (Figure 3) and relatively small acquirers (Figure 4) from van den Honert et al. (1988).

In Figure 3 it will be readily seen that major peaks in the CAAR plot occurred approximately 42 weeks and 26 weeks prior to the merger announcement. These correspond to time point $\mathrm{E}$ and time point $\mathrm{H}$ respectively in the covariance biplot, where the biplot movement is sharply towards point 9. Major troughs in the CAAR plot occurred in weeks 30 and 15 prior to the announcement, which correspond to time points $G$ and $L$ respectively in the biplot, where the movement is away from point 9. After the peak in week 26 prior to the announcement there follows a 14-week downward movement in CAAR followed by a strong upward movement in the 13-week period before the merger announcement. This is mirrored by time points $\mathrm{H}$ to $\mathrm{O}$ in the biplot which first move strongly away from point 9 and then strongly towards point 9 . The rapid erosion of the CAAR's after the announcement is represented by points time $P$ to $d$ which are consistently moving away from point 9 , indicating a decrease in relative strength of that characteristic. A similar comparison with the

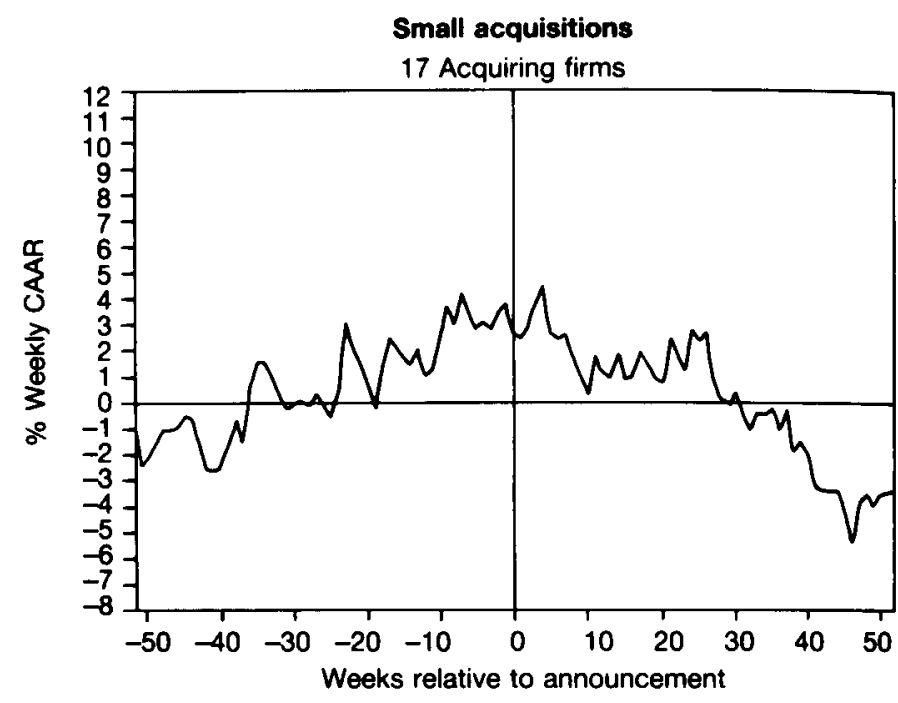

Figure 4 CAAR plot for relatively small acquiring firms (Source: van den Honert et al., 1988)

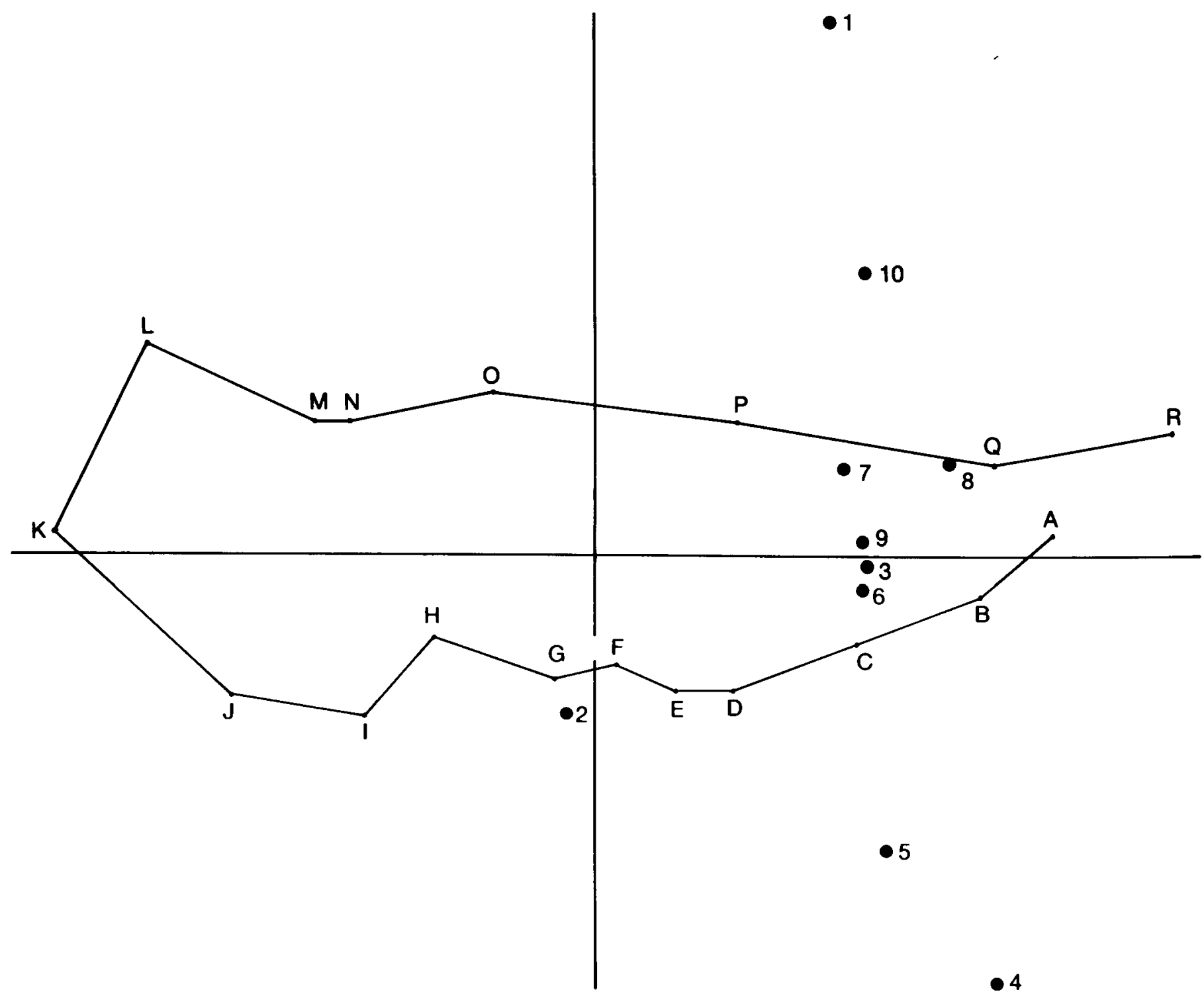

Figure 5 Covariance biplot for two levels of five characteristics of target firms over the period 15 months prior to merger until three months after merger 
Table 2 Correlation matrix (standard deviations on diagonal) for target firms

\begin{tabular}{lrrrrrrrrrrrr}
\hline Small size & 0,074 & & & & & & & & \\
Large size & $-0,099$ & 0,028 & & & & & & & \\
Small beta & 0,707 & 0,329 & 0,062 & & & & & & & \\
Large beta & 0,381 & 0,271 & 0,870 & 0,087 & & & & & & \\
Small prior holdings & 0,460 & 0,374 & 0,919 & 0,954 & 0,068 & & & & & \\
Large prior holdings & 0,651 & 0,366 & 0,884 & 0,781 & 0,838 & 0,064 & & & & \\
Related mergers & 0,683 & $-0,001$ & 0,809 & 0,676 & 0,678 & 0,781 & 0,049 & & & \\
Unrelated mergers & 0,618 & $-0,036$ & 0,815 & 0,784 & 0,786 & 0,867 & 0,896 & 0,080 & & \\
Share exchange & 0,494 & $-0,016$ & 0,792 & 0,855 & 0,805 & 0,798 & 0,877 & 0,942 & 0,060 & \\
Cash exchange & 0,712 & $-0,065$ & 0,779 & 0,595 & 0,652 & 0,775 & 0,913 & 0,894 & 0,782 & 0,065 \\
\hline
\end{tabular}

CAAR plot for the relatively small acquirers (Figure 4) shows peaks occurring in weeks 44,34 , and 23 before the merger ànnouncement, and in week 26 after the announcement which correspond to time points $D, G, I$ and $U$ respectively in the biplot, all extremely close to point 1.

Troughs in CAAR in Figure 4 occur in weeks 41, 26, 12 before the merger announcement and in week 10 after the announcement which correspond to time points $E$, $H, L$ and $Q$ respectively, which are all at local extreme points of the biplot, i.e. as far from point 1 as the plot will allow.

A similar interpretation can be made of the covariance biplot for the target firms for the 15 months before the merger and the 3 months after the merger. The biplot is presented in Figure 5.

The quality of the fit of this biplot in two dimensions is $88,9 \%$, i.e. an acceptable fit. Firstly it will be seen that target firms with large systematic risk prior to the merger and those that are small relative to the acquirer have the largest standard deviation, or risk. This is in general agreement with the standard deviations shown in Table 2.

The targets which are large relative to their acquirers have by far the smallest risk. Related targets, those acquired by share exchange, targets with small systematic risk prior to the merger and those targets in which the acquircrs have a controlling interest prior to the merger have a similar total risk, approximately twice that of the relatively large targets. In Figure 5 it will be seen groupings consisting of targets with small beta coefficient prior to the merger, related and unrelated targets, share exchange targets and those in which the acquirer had large prior holdings are highly interrelated since they lie close together, each pair subtending a small angle at the origin. In fact Table 2 shows that all these correlations are between 0,781 and 0,942 , and thus the average residuals of these groupings all follow a similar trend. This is consistent with the CAAR plots in van den Honert et al. (1988). However the single largest correlation is between targets with large beta coefficient prior to the merger and those targets in which the acquirer had only a small prior holding (correlation = $0,954)$. The relatively large target grouping is the only one to plot on the left hand side of the diagram, and thus has low or negative correlations with all the other groupings (between $-0,099$ and 0,374 ). This grouping (lying in the third quadrant) has negative correlation with almost all those groupings lying in the opposite (first) quadrant.

Turning to the performance of the groupings through time it will be seen that initially (time points $A$ to $K$ ) there is a steady decrease in average residuals of all groupings concerned except for the targets which are relatively large, in which the average residuals actually increased for the first six months. Indeed, van den Honert et al. (1988) found this grouping to be the only target group which exhibited consistently positive CAAR's for any period of time prior to merger. This decrease in average residuals persists until some four months prior to the merger announcement when there is a sudden reversal of movement towards all the groupings (time points $\mathrm{L}$ to $\mathrm{R}$ ) implying a strong gain in the residuals of all characteristics. The timing of this movement is exactly what is to be found in van den Honert et al., 1988 when the CAAR plots experienced an upward surge some $12-16$ weeks prior to the merger. However, this movement is least noticeable in the target firms which are large relative to the acquirers. This stengthening continues until delisting occurs.

\section{Summary and conclusions}

The relative movements of two different levels of five characteristics of acquiring and target firms immediately before and after merger have been demonstsrated on a single diagram by means of the covariance biplot. Alternative methods of analysing the role played by various characteristics of the acquiring target firms have considered each characteristic in isolation and their relative effect has been effectively ignored. Results produced in this paper are consistent with those produced by the cumulative average abnormal return approach, and yet have the advanlage of providing information as to the risks and co-movements of each of the characteristics.

The value of this study lies in the fact that several characteristics of merger activity have been analysed simultaneously, yielding information related to the time of the merger announcement for acquiring and target firms which could not have been obtained by standard univariate methods. 


\section{Acknowledgements}

Financial assistance rendered by the Human Sciences Research Council towards the cost of this research is hereby acknowledged. Opinions expressed or conclusions arrived at are those of the authors and not necessarily those of the HSRC.

\section{References}

Affleck-Graves, J.F., Flach, T.P., \& Jacobson, A.S. 1988. The Effect of Merger Announcements on the Share Prices of the Acquired and Acquiring Companies. S. Afr. J. Bus. Mgmt., vol. $19,147-154$.

Barr, G.D.I. \& Affleck-Graves, J.F. 1987. The Covariance Biplot and Stock Market Data: An Alternative Relative Strength Chart. S. Afr. J. Bus. Mgmt., vol. 18, 46-50.

Bhana, N. 1987. Take-over Announcements and Insider Trading Activity on the Johannesburg Stock Exchange. $S$. Afr. J. Bus. Mgmt., vol. 18, 198-208.

Dodd, P. 1980. Merger Proposals, Management Discretion and Stockholder Wealth. J. Fin. Econ., vol. 8, 105-138.

Fama, E.F., Fisher, L., Jensen, M. \& Roll, R. 1969. The Adjustment of Stock Prices to New Information. Intern. Econ. Rev., February 1969, 1-21.

Gabriel, K.R. 1971. The Biplot Graphic Display of Matrices with Application to Principal Component Analysis. Biometrika, vol. 58, 453-467.

Gabriel, K.R. 1972. Analysis of Meteorologica; Data by Means of Canonical Decomposition and Biplots. J. Appl. Meteorology, vol. 11, 1071-1077.

Gabriel, K.R. 1981. Biplot Display of Multivariate Matrices for Inspection of Data and Diagnosis. In: Barnett, V. (ed.) Interpreting Multivariate Data, 147-174. Chichester, U.K.: Wiley.

Greenacre, M.J. \& Underhill, L.G. 1982. Scaling a data matrix in low dimensional Euclidean space. In: Hawkins, D.M. (ed.) Topics in applied multivariate analysis, 183-268). Cambridge, U.K.: Cambridge University Press.

Greenacre, M.J. 1984. Theory and Applications of correspondence analysis. Academic Press.

Halpern, P.J. 1973. Empirical Estimates of the Amount and Distribution of gains to Companies in Mergers. J. Bus., October 1973, 554-575.

Langetieg, T. 1978. An Application of a Three Factor Performance Index to Measure Stockholder Gains from Merger. J. Fin. Econ., vol. 6, 365-384.

Mandelker, G. 1974. Risk and Return: the Case of Merging Firms. J. Fin., vol. 1, 303-335.

Markowitz, H.M. 1952. Portfolio Selection. J. Fin., vol. 7, 77-91.

Van den Honert, R.C., Barr, G.D.I., Affleck-Graves, J.F. \& Smale, G. 1988. Merger Announcements and Share Price Return - the Role of the Relationship between Acquiring and Target Firms. S. Afr. J. Bus. Mgmt., vol. 19, 1-10.
Appendix 1 Acquiring firms

No. Acquiring firm

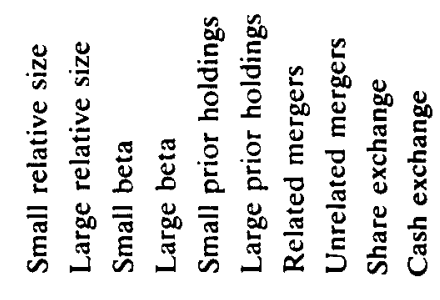

\begin{tabular}{|c|c|c|c|c|c|c|c|}
\hline \multirow{2}{*}{$\begin{array}{l}\text { Anglo American Corp. } \\
\text { Anglo American Indust. Corp. }\end{array}$} & \multicolumn{2}{|l|}{$\mathrm{x}$} & & \multirow[t]{2}{*}{$\mathrm{x}$} & & \multirow{2}{*}{$\begin{array}{l}x \\
x\end{array}$} & $\mathrm{x}$ \\
\hline & $\mathbf{x}$ & & & & & & $x$ \\
\hline Anglo American Properties & $\mathbf{x}$ & & & $\mathbf{x}$ & $\mathbf{x}$ & & $\mathrm{x}$ \\
\hline Barlow Rand & $\mathbf{x}$ & & $\mathbf{x}$ & $\mathbf{x}$ & & $\mathbf{x}$ & \\
\hline Blue Circle & $\mathrm{x}$ & & $\mathrm{x}$ & $\mathrm{x}$ & & $\mathrm{x}$ & $\mathrm{x}$ \\
\hline CG Smith Sugar & $\mathbf{x}$ & $\mathbf{x}$ & & & $\mathbf{x}$ & & \\
\hline Amalgamated Retail & $\mathbf{x}$ & & $\mathbf{x}$ & $\mathbf{x}$ & $x$ & & $\mathbf{x}$ \\
\hline Anglo Alpha Cement & & $\mathbf{x}$ & & $\mathrm{x}$ & & $\mathbf{x}$ & $\mathbf{x}$ \\
\hline Dorman Long & $\mathbf{x}$ & & & & $\mathbf{x}$ & & $\mathbf{x}$ \\
\hline Federale Volksbeleggings & & & $\mathbf{x}$ & & & $\mathrm{x}$ & \\
\hline General Mining & $\mathbf{x}$ & & & & & $\mathbf{x}$ & $\mathbf{x}$ \\
\hline Hunt Leuchars and Hepburn & & $x$ & & $\mathrm{x}$ & & $\mathrm{x}$ & \\
\hline Johannesburg Cons. Invest. & $\mathbf{x}$ & & $\mathbf{x}$ & & & $\mathbf{x}$ & $\mathbf{x}$ \\
\hline Kohler & $\mathbf{x}$ & $\mathbf{x}$ & & $\mathrm{x}$ & $\mathrm{x}$ & & $\mathbf{x}$ \\
\hline Metal Box & $\mathbf{x}$ & & & & $\mathbf{x}$ & & $\mathbf{x}$ \\
\hline Nampak & $\mathbf{x}$ & & & $\mathrm{x}$ & $\mathrm{x}$ & & $\mathbf{x}$ \\
\hline Rembrandt Group & $\mathrm{x}$ & & $\mathbf{x}$ & & & $\mathbf{x}$ & $\mathbf{x}$ \\
\hline Sage Holdings & $\mathrm{x}$ & & & $\mathrm{x}$ & & $\mathbf{x}$ & $x$ \\
\hline Sam Steel & $\mathrm{x}$ & & $\mathbf{x}$ & $x$ & $x$ & & \\
\hline Union Platinum & $\mathrm{x}$ & & $\mathbf{x}$ & $\mathrm{x}$ & & $\mathbf{x}$ & $\mathrm{x}$ \\
\hline Seardel & & & $\mathrm{x}$ & $\mathrm{x}$ & $\mathbf{x}$ & & $x$ \\
\hline Sentrachem & & & $\mathbf{x}$ & $x$ & $x$ & & $\mathrm{x}$ \\
\hline Metkor Investments & $\mathbf{x}$ & $\mathrm{x}$ & & & & $\mathbf{x}$ & $x$ \\
\hline Tongaat Hulett & & & & $x$ & & $\mathbf{x}$ & $\mathrm{x}$ \\
\hline Union Corporation & $\mathrm{x}$ & $x$ & & $\mathrm{x}$ & & $\mathrm{x}$ & $\mathbf{x}$ \\
\hline Volkskas Group & $\mathbf{x}$ & & $\mathbf{x}$ & $\mathbf{x}$ & $\mathbf{x}$ & & $\mathrm{x}$ \\
\hline W \& A Investments & $\mathrm{x}$ & & $\mathbf{x}$ & $\mathbf{x}$ & $\mathbf{x}$ & & $\mathbf{x}$ \\
\hline Welkom GM Co Ltd & $\mathbf{x}$ & $\mathbf{x}$ & & $\mathbf{x}$ & $\mathbf{x}$ & & $\mathbf{x}$ \\
\hline Woolworths & $\mathrm{x}$ & & $x$ & $\mathbf{x}$ & $\mathbf{x}$ & & \\
\hline Kirsch Trading & $\mathbf{x}$ & & $\mathbf{x}$ & $\mathbf{x}$ & & $\mathbf{x}$ & $\mathbf{x}$ \\
\hline Lucem Holdings & $\mathrm{x}$ & $\mathrm{x}$ & & & & $\mathbf{x}$ & \\
\hline East Driefontein & $\mathbf{x}$ & $\mathbf{x}$ & & $\mathbf{x}$ & $\mathrm{x}$ & & $\mathbf{x}$ \\
\hline CNA Investments & $x$ & $\mathbf{x}$ & & $\mathbf{x}$ & & $\mathbf{x}$ & $\mathbf{x}$ \\
\hline
\end{tabular}

Appendix 2 Target firms

No. Target firm

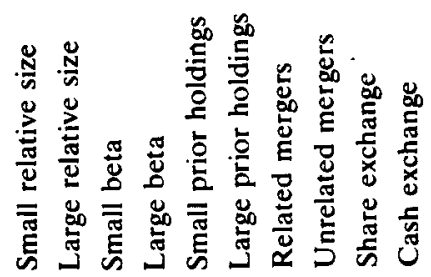

Bruynzeel Plywood
Waterval Platinum
Potgietersrus Platinum
Geduld Investments
Rand Selections
Hippo Holdings

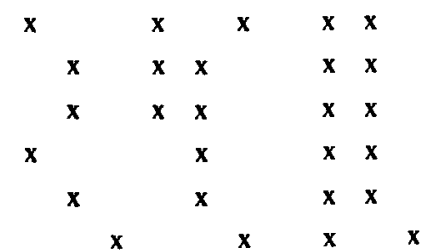


No. Target firm

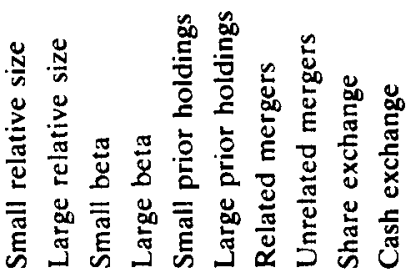

Hubert Davies

Ryan Nigel Holdings

Burlington Hosiery

CJ Fuchs

Metal Rolling \& Tube

Illovo Sugar

Fowler Holdings

Oude Mcester

15 Bus Industries SA

16 Steel and Barnet

17 Hart L.td

18 Wispeco

19 Federale Kunsmis

20 Brick and Clay Holdings

21 Sorec

22 Free State Saaiplaas

23 Dubin Investments

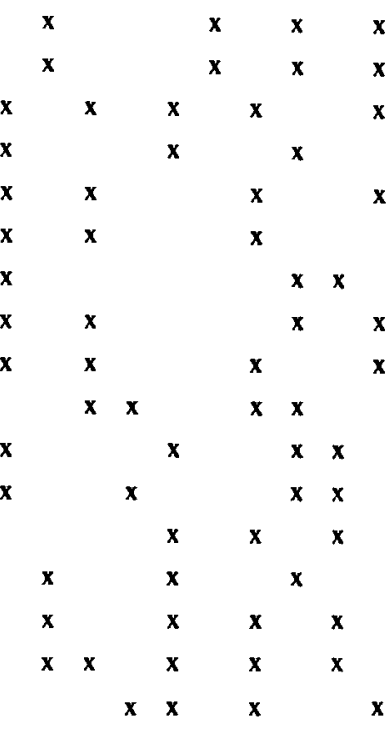

No. Target firm

\begin{tabular}{ll}
\hline 24 & Truworths \\
25 & Tavistock Collieries \\
26 & West Driefontein \\
27 & Bank OFS \\
28 & WF Johnstone \\
29 & Tongaat \\
30 & DRG (SA) \\
31 & Gallo Africa \\
32 & Xactics \\
33 & Sentrust \\
34 & SA Druggists \\
35 & Tongaat Corogroup \\
36 & Metcash \\
37 & Russel Holdings \\
38 & ABC Shoe Company \\
39 & Scottish Cables \\
40 & Union Corporation
\end{tabular}

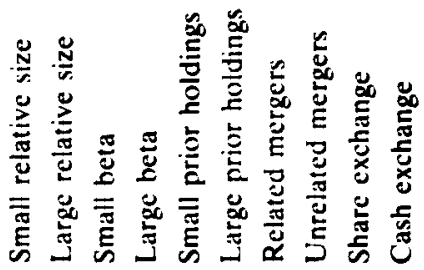

$\begin{array}{ccccccc}\mathbf{x} & \mathbf{x} & \mathrm{x} & \mathrm{x} & & \\ & \mathrm{x} & & & \mathrm{x} & \mathrm{x} \\ \mathbf{x} & & \mathbf{x} & \mathbf{x} & \mathrm{x}\end{array}$
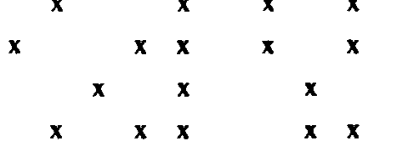

$\begin{array}{llllll} & x & x & x & & x\end{array}$

$x \quad x \quad x \quad x$
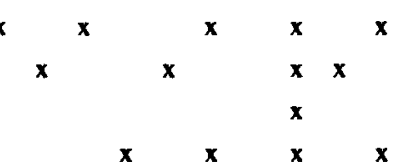

$\begin{array}{lllllllll} & \mathbf{x} & \mathbf{x} & & \mathbf{x} & & \mathbf{x} & \mathbf{x} & \\ \mathbf{x} & & \mathbf{x} & \mathbf{x} & & \mathbf{x} & \mathbf{x} & \\ \mathbf{x} & & \mathbf{x} & & \mathbf{x} & \mathbf{x} & & & \mathbf{x} \\ & \mathbf{x} & & \mathbf{x} & \mathbf{x} & & \mathbf{x} & \\ & & & & & \mathbf{x} & \mathbf{x} & \end{array}$

